\title{
Influence of Different Packaging Materials on Occurrence of Pathogens in Pear Fruit during Storage
}

\author{
Vikram Singh", O.P. Dudi, J.K. Sandooja and R.K. Goyal
}

Chaudhary Charan Singh Haryana Agricultural University, Hisar-125004, Haryana, India

*Corresponding author

\section{A B S T R A C T}

\section{Keywords}

Pear, Polyethylene,

Corrugated fiber board boxes,

Patharnakh, Kashmirinakh,

Baggugosha, Zero Energy Chamber

Article Info

Accepted:

12 February 2018

Available Online:

10 March 2018
The present study aimed at enhancing the shelf life of pear fruits. The fruits of pear varieties namely Patharnakh, Kashmirinakh and Baggugosha were stored under zero energy cool chamber (ZECC) storage using different types of packaging materials i.e. corrugated fiber board boxes (CFB), individual fruit packing and in $1 \mathrm{~kg}$ packing in polyethylene (PE) bags of $0.01 \mathrm{~mm}$ and $0.05 \mathrm{~mm}$ thickness. Irrespective of the treatments, a continuous decrease in specific gravity of the fruits was observed with the lapse of time. Of the three varieties, the Patharnakh fruits had maximum shelf life. Individual packing of fruits in polyethylene bags of $0.01 \mathrm{~mm}$ and storage under ZECC proved to be most effective treatment in checking the decay loss. Whereas, the maximum degradation of fruits was found in CFB boxes stored at room temperature. Therefore, ZECC storage with suitable packaging material has great prospects in hot regions for short term preservation of fruits soon after harvest.

\section{Introduction}

Pear (Pyrus communis L.) is a member of family Rosaceae and is just next to apple in terms of importance, acreage, production and varietal diversity among different temperate fruits in India. Pear is a fruit of temperate habitat but some low chilling pear varieties like Patharnakh, Kashmirinakh and Baggugosha have also enabled its cultivation in the subtropical regions of Punjab and Haryana states.

The hot temperature in the months of JulyAugust triggers rapid ripening of fruits which also reduces the shelf life of pear fruit and is a serious constraint in their efficient handling and transportation. Polythene bags create a modified atmospheric condition inside the package, which lowers down the concentration of $\mathrm{O}_{2}$ and increases the concentration of $\mathrm{CO}_{2}$. The modified gaseous composition of the package helps in slowing down the physiological processes like respiration and transpiration, reduces the physiological loss of fruit weight and helps in maintaining the freshness of fruits for longer period of time.

Refrigerated cold storage is considered to be the best method for storage of fruits and vegetables. However, this method is highly energy intensive, requires large initial capital investment and is also not suitable for on-farm storage in the rural areas. Considering the 
acute energy shortage in rural areas, the low cost, on-farm scientific storage structures like zero energy cool chamber (ZECC) has better use potential. The ZECC was devised at IARI by Roy and Khurdia (1986) which works on the principle of evaporative cooling. The structure is built from easily available low cost materials like brick, sand, khaskhas, bamboo, gunny bags etc.

The ZECC due to evaporative cooling helps in maintaining the inside temperature 8 to $10^{\circ} \mathrm{C}$ lower than the outside environment and maintains relative humidity nearly $90-95$ per cent. The ZECC have been found successful for enhancing the storage life of Kinnow (Pal et al., 1997) and banana (Mustaffa et al., 2005). Hitherto, no systematic work has been done in pear to enhance shelf life of fruits using ZECC and different types of packaging materials. So, the purpose of conducting this experiment was to investigate the influence of different packaging materials on pear varieties under ZECC.

\section{Materials and Methods}

The experiment was conducted in the PostHarvest Laboratory, Department of Horticulture, Chaudary Charan Singh Haryana Agricultural University (CCS HAU), Hisar. The fruits of the three varieties viz. Patharnakh, Baggugosha and Kashmirinakh were harvested at maturity with the help of a secateur. Then fruits were packed in the corrugated fiber board (CFB) boxes of $2 \mathrm{~kg}$ capacity using newspapers as cushioning material (control), polyethylenes of individual fruit packing (IFP) and $1 \mathrm{~kg}$ capacity bags of $0.01 \mathrm{~mm}$ and $0.05 \mathrm{~mm}$ thickness.

The half of the packed fruits were stored at ambient temperature $\left(32 \pm 4^{\circ} \mathrm{C}\right.$ and R.H. $70-$ $75 \%$ ), while the remaining half stored in ZECC of storage dimensions $195 \times 135 \times 67.5$ $\mathrm{cm}$ for 10 days. The floor of ZECC was made up of a single layer of bricks, the side walls with a double layer of bricks, the space (7.5 $\mathrm{cm})$ in between the bricks was filled with sand. The top of storage space was covered with wet gunny bags in bamboo structure. Sprinkling of water twice a day was enough to maintain the low temperature and high humidity $\left(23.2 \pm 3^{\circ} \mathrm{C}\right.$ and R.H. 90-95\%). All the treatments were replicated four times taking each box as one replication.

\section{Observations}

The data on loss due to decay were recorded in the fruits taken from replication 1 to 3 on $2^{\text {nd }}, 4^{\text {th }}, 6^{\text {th }}, 8^{\text {th }}$ and $10^{\text {th }}$ day of storage.

During storage, the fruits showing rotting symptoms due to over ripening and pathological infection were considered decayed. The per cent decay loss was worked out by the following formula:

Weight of decayed fruits

Decay Loss $(\%)=$------------------ X 100

Initial weight of fruit at the time of packing

The decay causing organisms were identified with the collaboration of the Department of Plant Pathology CCS HAU Hisar.

The data on parameter of specific gravity of the fruits were recorded on 3 fruits randomly picked from $4^{\text {th }}$ replication on every alternate day.

The specific gravity was recorded through water displacement method and was calculated by using the following formula:

Specific gravity $=\frac{\text { Density of fruit }}{\text { Density of water }}$

The density of fruits in $\mathrm{g} \mathrm{cm}^{-3}$ was worked out by the weight of the fruits to their volume. 


\section{Statistical analysis}

The experiment was laid out in a Complete Randomized Design (CRD) and treatments were compared using ANOVA procedure at 5 per cent level of significance.

\section{Results and Discussion}

\section{Decay loss}

At the end of the storage, the minimum decay loss in Patharnakh (18.16\%) and Baggughosa (20.07and $20.12 \%$ ) were observed in the treatments of individual fruits packed in $\mathrm{PE}$ $(0.01$ and $0.05 \mathrm{~mm})$ bags and stored in ZECC (Table 1). On the other hand, the minimum loss due to decay in Kashmirinakh was observed in the $1 \mathrm{~kg}$ fruits packed in PE $(0.05$ $\mathrm{mm}$ ) bags stored at room temperature and at par with PE $0.01 \mathrm{~mm}$ at ZECC. The maximum decay loss $(32.14 \%)$ was noticed in variety Baggugosha packed in CFB boxes at room temperature (control).

Irrespective of the treatment, the decay associated loss increased in all varieties with the advancement of storage period. This may be due to exposure of fruits to micro-floras during storage.

The condensation of moisture on the surface of fruits, storage humidity due to transpiration, anaerobic condition and breakdown of enzymes etc. help in multiplication of micro flora. The increase in decay loss during prolonged storage is in agreement with the earlier findings of Nath et al., (2012) and Kaur et al., (2013) in pear and Mahajan et al., (2015) in peach.

Comparatively lower decay loss under polyethylene packing than CFB boxes can be attributed to the isolation of fruits from the open environment and only few microorganisms could diffuse into the polybags. On the other hand the fruits were fully exposed to the microflora in CFB boxes. Similar decrease in decay with use of polythene bags has also been reported by Kaur et al., (2013). Further, the fruits of variety Baggugosha were found more prone to decay loss as compare to Patharnakh. Whereas, Kasmirinakh fruits in PE $0.05 \mathrm{~mm}$ of $1 \mathrm{~kg}$ bag stored at room temperature and PE $0.01 \mathrm{~mm}$ of $1 \mathrm{~kg}$ bag at ZECC showed lower decay loss and that could be due to better suitability of these films in vapour transmission and gaseous exchange for Kashmirinakh fruits.

\section{Specific gravity}

A decreasing trend in specific gravity was seen during storage of 10 days in all the varieties irrespective of treatments (Table 2).

The effect of packaging materials on specific gravity of Patharnakh and Kashmirinakh fruits was found non-significant.

However, in case of Baggugosha maximum specific gravity on $10^{\text {th }}$ day of storage (1.034) was observed in individual fruits packed in PE bags of $0.01 \mathrm{~mm}$ and stored in zero energy cool chamber.

Polyethylene packed fruits retained higher specific gravity as compare to CFB boxes. This may be due to lower PLW in polythene packed fruits as compare to control i.e. CFB boxes.

Decrease in specific gravity during storage may be correlated with decrease in fruit weight.

Arya (2001) also reported decreasing trend of specific gravity in Kinnow Mandrin. Specific gravity of Patharnakh and Kashmirinakh fruits was higher than Baggugosha, which could be correlated with lower weight loss in these varieties as compared to Baggugosha. 
Table.1 Effect of packaging materials on decay loss $(\%)$ during storage of pear at room temperature and zero energy chamber

\begin{tabular}{|c|c|c|c|c|c|c|c|c|c|c|c|c|c|c|c|c|}
\hline Sr. & Treatments & & & tharna & & & & & shmirin & & & & & aggugos & & \\
\hline & & & Day & after st & age & & & & after $s$ & rage & & & & after st & age & \\
\hline & & 2 & 4 & 6 & 8 & 10 & 2 & 4 & 6 & 8 & 10 & 2 & 4 & 6 & 8 & 10 \\
\hline 1. & CFBboxes Room(Control) & 5.17 & 8.32 & 12.19 & 18.55 & 24.10 & 5.74 & 8.77 & 12.98 & 19.63 & 27.42 & 6.90 & 9.02 & 14.21 & 22.17 & 32.14 \\
\hline 2. & CFBZEC & 4.70 & 7.65 & 10.31 & 15.73 & 21.62 & 5.10 & 7.91 & 11.86 & 17.34 & 24.31 & 5.32 & 8.76 & 12.65 & 19.72 & 26.10 \\
\hline 3. & PE0.01 mm(IFP)Room & 3.54 & 5.66 & 8.85 & 13.80 & 18.33 & 3.82 & 5.89 & 10.15 & 16.29 & 21.26 & 4.38 & 6.67 & 10.51 & 17.22 & 23.44 \\
\hline 4. & PE0.01 mm(IFP)ZEC & 2.94 & 5.41 & 8.52 & 13.20 & 18.16 & 2.26 & 4.42 & 9.18 & 15.74 & 19.68 & 4.29 & 5.22 & 9.14 & 13.26 & 20.12 \\
\hline 5. & PE0.05 mm(IFP)Room & 3.25 & 5.59 & 8.46 & 12.78 & 19.25 & 3.70 & 5.70 & 10.72 & 13.90 & 20.10 & 5.76 & 6.38 & 9.44 & 15.61 & 22.10 \\
\hline 6. & PE0.05mm(IFP)ZEC & 2.90 & 5.26 & 8.30 & 12.69 & 18.20 & 3.34 & 5.07 & 10.68 & 14.12 & 20.21 & 4.20 & 6.77 & 8.96 & 14.93 & 20.07 \\
\hline 7. & PE0.01 mm(1 kg bag) Room & 3.17 & 6.75 & 9.40 & 13.57 & 19.41 & 3.63 & 4.96 & 11.83 & 14.04 & 21.15 & 5.06 & 6.92 & 10.33 & 15.25 & 22.31 \\
\hline 8. & PE0.01 mm(1 kg bag)ZEC & 2.91 & 6.62 & 9.08 & 13.45 & 19.22 & 2.32 & 4.46 & 10.08 & 15.28 & 19.23 & 5.25 & 7.13 & 11.08 & 14.69 & 20.98 \\
\hline 9. & PE0.05mm(1 kgbag) Room & 3.22 & 5.34 & 9.15 & 13.50 & 19.28 & 2.56 & 4.38 & 11.06 & 14.10 & 19.14 & 4.80 & 5.61 & 11.26 & 14.23 & 21.09 \\
\hline 10. & PE0.05 mm(1kgbag)ZEC & 3.10 & 5.27 & 8.91 & 13.37 & 19.06 & 2.20 & 4.21 & 10.90 & 16.33 & 20.49 & 4.09 & 5.35 & 9.05 & 14.07 & 20.95 \\
\hline & $\mathrm{CD}$ at $5 \%$ & 0.09 & 0.09 & 0.26 & NS & 0.09 & 0.14 & 0.13 & 0.41 & 0.13 & 0.17 & 0.33 & 0.33 & 0.28 & 1.58 & 0.77 \\
\hline & Mean & 3.49 & 6.19 & 9.32 & 14.06 & 19.66 & 3.47 & 5.58 & 10.94 & 15.68 & 21.30 & 5.01 & 6.78 & 10.66 & 16.12 & 22.93 \\
\hline $\begin{array}{l}\text { Ove } \\
\text { Ror }\end{array}$ & all mean for & 3.67 & 6.33 & 9.61 & 14.44 & 20.07 & 3.89 & 5.94 & 11.35 & 15.59 & 21.81 & 5.38 & 6.92 & 11.15 & 16.90 & 24.22 \\
\hline & ZEC & 3.31 & 6.04 & 9.02 & 13.69 & 19.25 & 3.04 & 5.21 & 10.54 & 15.76 & 20.78 & 4.63 & 6.65 & 10.18 & 15.33 & 21.64 \\
\hline & $\mathrm{CD}$ at $5 \%$ Room & 2.75 & Storage & NS & & & & & & & & & & & & \\
\hline & ZEC & 0.21 & & & & & & & & & & & & & & \\
\hline
\end{tabular}

$\mathrm{CFB}=$ Corrugated fibre board boxes, Room = Room temperature, IFP = Individual Fruit Packing, PE = Polyethylene, ZEC = Zero Energy Chamber 
Table.2 Effect of packaging materials on specific gravity during storage of pear at room temperature and zero energy chamber

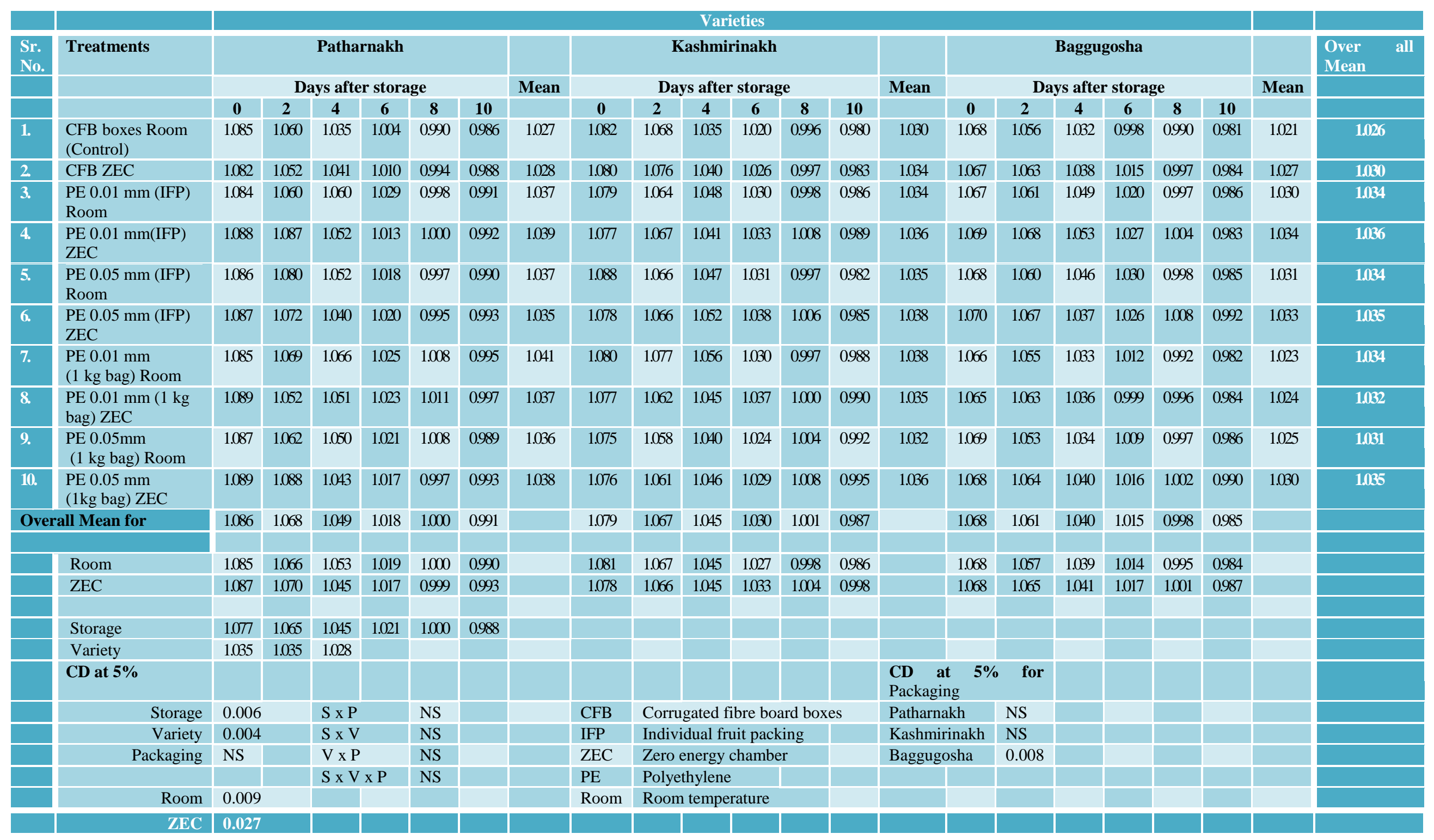


Table.3 Effect of packaging materials on occurrence of pathogens during storage of pear at room temperature and zero energy chamber

\begin{tabular}{|c|c|c|c|c|c|c|c|c|c|c|c|c|c|c|c|c|}
\hline Sr. & Treatments & \multicolumn{5}{|c|}{ Patharnakh } & \multicolumn{5}{|c|}{ Kashmirinakh } & \multicolumn{5}{|c|}{ Baggugosha } \\
\hline & & \multicolumn{5}{|c|}{ Days after storage } & \multicolumn{5}{|c|}{ Days after storage } & \multicolumn{5}{|c|}{ Days after storage } \\
\hline & & 2 & 4 & 6 & 8 & 10 & 2 & 4 & 6 & 8 & 10 & 2 & 4 & 6 & 8 & 10 \\
\hline 1. & CFBboxesRoom(Control) & PPB & PPB & PPB & PPB & PPB & PPB & PPB & PPB & PPB & PPB & PPB & PPB & PPB & PPB & PPB \\
\hline 2. & CFBZEC & PPB & PPB & PPB & PPB & PPB & PPB & PPB & PPB & PPB & PPB & PPB & PPB & PPB & PPB & PPB \\
\hline 3. & PE0.01 mm(IFP)Room & $\mathrm{P}$ & PB & PB & PPB & PPB & PB & PB & PPB & PPB & PPB & PB & PPB & PPB & PPB & PPB \\
\hline 4. & PE0.01 mm(IFP)ZEC & $\mathrm{P}$ & PB & PB & PB & PPB & PB & PB & PPB & PPB & PPB & PB & PPB & PPB & PPB & PPB \\
\hline 5. & PE0.05 mm(IFP)Room & $\mathrm{P}$ & PB & PB & PPB & PPB & PB & PB & PPB & PPB & PPB & PB & PPB & PPB & PPB & PPB \\
\hline$\overline{6 .}$ & PE0.05 mm(IFP)ZEC & $\mathrm{P}$ & PB & PB & PB & PPB & PB & PB & PPB & PPB & PPB & PB & PPB & PPB & PPB & PPB \\
\hline 7. & PE0.01 mm(1 kgbag) Room & $\mathrm{P}$ & PB & PB & PPB & PPB & PB & PB & PPB & PPB & PPB & PB & PPB & PPB & PPB & PPB \\
\hline 8. & PE0.01 mm(1 kgbag)ZEC & $\mathrm{P}$ & PB & PB & PPB & PPB & PB & PB & PPB & PPB & PPB & PB & PPB & PPB & PPB & PPB \\
\hline 9. & PE0.05mm(1 kgbag) Room & $\mathrm{P}$ & PB & PB & PPB & PPB & PB & PB & PPB & PPB & PPB & PB & PPB & PPB & PPB & PPB \\
\hline 10. & PE0.05 mm(1kgbag)ZEC & $\mathrm{P}$ & PB & PB & PPB & PPB & PB & PB & PPB & PPB & PPB & PB & PPB & PPB & PPB & PPB \\
\hline \multicolumn{2}{|c|}{$\mathbf{P}=$ Penicillium sp. } & \multicolumn{6}{|c|}{$\mathrm{CFB}=$ Corrugated fibre board boxes } & Room & \multicolumn{4}{|c|}{$=$ Room temperature } & & & & \\
\hline \multicolumn{2}{|c|}{$\mathbf{P}=$ Physalospora sp. } & \multicolumn{5}{|c|}{ IFP = Individual fruit packing } & & & & & & & & & & \\
\hline \multicolumn{2}{|c|}{ B = Botrytis sp. } & \multicolumn{5}{|c|}{ ZEC = Zero Energy Chamber } & & & & & & & & & & \\
\hline & & \multicolumn{5}{|c|}{ PE = Polyethylene } & & & & & & & & & & \\
\hline
\end{tabular}




\section{Pathological observations}

Fruits of all the varieties were found infected with Penicillium sp., Physalospora sp. and Botrytis sp. Low incidence of pathogens was observed in PE $0.01 \mathrm{~mm}$ and PE $0.05 \mathrm{~mm}$ of individual fruit packing at zero energy chamber storage. Whereas, aggravated host pathogen complex was found in CFB boxes at room temperature as well as at zero energy chamber storage (Table 3).

The results are in accordance with reports of Logrieco et al., (2003), Baszczyk and Buczek (2004) and Lennox and Spotts (2004) on various fungi responsible for decay in pear fruits during storage. This might be due to the reason that fruits are living entities and contain sufficient stored food material and are exposed to various micro flora during storage.

\section{References}

Arya, Tejbir; 2001. Studies on the effect of different packaging materials on shelf life of Kinnow Mandarin. M.Sc Thesis, CCS Haryana Agricultural University, Hisar, India.

Baszczyk, J. and Buczek, M. 2004. Study on the occurrence of fungal diseases in pear during cold storage. Folia Universitatis Agriculturae Stetinensis, Agricultura, 96: 29-32.

Kaur, Kirandeep; Dhillon, W.S. and Mahajan B.V.C. 2013. Feb. Effect of different packaging materials and storage intervals on physical and biochemical characteristics of pear. J Food Sci. Technol., 50(1):147-152.
Lennox, C.L. and Spotts, R.A. 2004. Timing of pre-harvest infection of pear fruit by Botrytis cinerea and the relationship to post-harvest decay. Plant Disease, 88 (5): 468-473.

Logrieco, A., Bottalico, A., Mule, G., Moretti, A. and Perrone, G. 2003. Epidemiology of toxigenic fungi and their associated mycotoxins for some Mediterranean crops. European Journal of Plant Pathology, 109 (7): 645-667.

Mahajan, B.V.C., Dhillon, W. S., Kumar, Mahesh and Singh, Bikramjit. June 2015.Effect of different packaging films on shelf life and quality of peach under super and ordinary market conditions. $J$. Food Sci. Technol., 52(6):3756-3762.

Mustaffa, M.M., Tanuja, P.B. and Krishnamoorthy, $\quad$ V., 2005. Standardization of carrier material as ethylene absorbent on shelf life of 'Rusthali' banana. J. Food Sci. Technol., Mysore; 42(1):104-106

Nath, A., Deka C. Bidyut; Singh, Akath; Patel, R.K., Paul D., Misra, L.K. and Ojha, H. 2012 Oct. Extension of shelf life of pear fruits using different packaging materials. J. Food Sci. Technol., 49(5):556-563.

Pal, R.K., Roy, S.K. and Srivastava, S. 1997.Storage performance of 'Kinnow' Mandarins in evaporative cool chambers and ambient condition. $J$. Food Sc. Technol., 34(3):200-203.

Roy, S.K. and Khurdiya, D.S. 1986. Studies on evaporatively cooled zero energy input cool chambers for the storage of horticultural produce. Ind. Fd. Packer; 40:26-31.

\section{How to cite this article:}

Vikram Singh, O.P. Dudi, J.K. Sandooja and Goyal, R.K. 2018. Influence of Different Packaging Materials on Occurrence of Pathogens in Pear Fruit during Storage. Int.J.Curr.Microbiol.App.Sci. 7(03): 1609-1615. doi: https://doi.org/10.20546/ijcmas.2018.703.194 